\title{
High-Skilled Services and Development in China*
}

\author{
Lei Fang (Federal Reserve Bank of Atlanta) \\ Berthold Herrendorf (Arizona State University)
}

February 13, 2019

\begin{abstract}
We document that the employment share of high-skilled services is much lower in China than in countries with similar GDP per capita. We build a model of structural change between goods, low-skilled services, and high-skilled services to account for this observation. We find that large distortions limit the size of high-skilled services in China. If they were removed, both high-skilled services and GDP per capita would increase considerably and the effects of technological progress and education on GDP per capita would be considerably larger. This suggests that distortions in high-skilled services importantly hold back the development of China.
\end{abstract}

Keywords: China; high-skilled services; structural change.

JEL classification: O41; O47; O51.

*Disclaimer: The views expressed here are the opinions of the authors only and do not necessarily represent those of the Federal Reserve Bank of Atlanta or the Federal Reserve System. 


\section{Introduction}

Since the start of the economic reforms in China in 1978, Chinese GDP per capita has grown by around $7 \%$ per year. This impressive growth performance involved improving the productivity of agriculture and moving large parts of the Chinese labor force into higher-productivity employment outside of agriculture, in particular in manufacturing. Dekle and Vandenbroucke (2012) and Cao and Birchenall (2013) offer detailed analyses of the Chinese reallocation from agriculture to non-agriculture. This is typically referred to as the first phase of structural change. Although many people in China still work in agriculture, and could also move to non-agriculture and thereby prolong the first phase of structural change, the question arises what the future will hold for all those who are already in non-agriculture. The historical experiences of structural change teach us that the first phase of structural change is followed by a second phase that involves moving more and more of the labor force into services until the services sector almost takes over the whole economy; see for example the evidence presented in Herrendorf et al. (2014).

Table 1: Employment Shares (in \%) at GDP pc similar to that of China

\begin{tabular}{lccc}
\hline Country, Year & $\begin{array}{c}\text { Low Skilled } \\
\text { Services }\end{array}$ & $\begin{array}{c}\text { High Skilled } \\
\text { Services }\end{array}$ & $\begin{array}{c}\text { High Skilled Services } \\
\text { over Total Services }\end{array}$ \\
\hline Argentina, 1995 & 38 & 29 & 43 \\
Brazil, 2009 & 40 & 23 & 36 \\
China, 2011 & $\mathbf{2 9}$ & 7 & $\mathbf{2 0}$ \\
Denmark, 1953 & 30 & 14 & 32 \\
France, 1959 & 21 & 22 & 50 \\
Hong Kong, 1975 & 35 & 12 & 25 \\
Italy, 1967 & 23 & 16 & 40 \\
Japan, 1967 & 28 & 18 & 39 \\
Malaysia, 1993 & 30 & 20 & 40 \\
Taiwan, 1979 & 28 & 12 & 30 \\
Thailand, 2006 & 27 & 11 & 28 \\
UK, 1954 & 32 & 19 & 37 \\
West Germany, 1960 & 26 & 15 & 37 \\
\hline Average & $\mathbf{3 0}$ & $\mathbf{1 7}$ & $\mathbf{3 5}$ \\
\hline
\end{tabular}

GDP per capita is computed from Penn World Tables 8.1. Employment shares are constructed from GGDC 10-sector database.

This paper is about the second phase of structural change in China. The potential of moving workers into services is particularly large in China because the Chinese service sector is small in comparison to other countries with similar GDP per capita. Table 1 compares the sectoral composition in China in 2011 with those in countries-year pairs that have similar GDP 
per capita as China. ${ }^{1}$ The table shows that the average employment share of the services sector (second plus third column) is $36 \%$ in China compared to an average of $47 \%$ in the other countries. The difference is particularly pronounced in high-skilled services. ${ }^{2}$ The high-skilled services sector has only $7 \%$ of the total employment in China compared to an average of $17 \%$ in the other countries with similar level of development. This amounts to only $1 / 5$ of total service employment being in high-skilled services in China compared to an average of more than $1 / 3$ in the other countries. So despite the fact that employment in goods production is comparatively large in China due to the large trade surpluses, it is still true that within Chinese services the high-skilled sector is comparatively underdeveloped.

The previous facts imply that the second phase of structural change in China will likely involve large movements into high-skilled services. To get some idea about the extent of the future development of high-skilled services, it is also useful to bring in the U.S. experience. Figure 1 plots the U.S. employment shares of agriculture, manufacturing, low-skilled services, and high-skilled services during 1850-2000. The figure shows the standard patterns of structural change, namely agriculture decreases over time while manufacturing first increases and then decreases. The figure also shows that the changes in the shares of low-skilled services were similar to those in manufacturing, except that the share of low-skilled services did not decline at the end. In contrast, the share of the high-skilled services sector took off some time after World War II and has been the largest and the only growing one since the 1970s. If the development experience of the U.S. economy is anything to go by, this suggests that developing a high-skilled services sector will become increasingly important for China as its economy develops.

Given this evidence, we ask why the high-skilled-services sector is underdeveloped in China and how it may develop in the future. Possible reasons include low productivity of high-skilled services, scarcity of high-skilled labor, or distortions in high-skilled services. There is a lively debate about which the dominant reason is. For example, Nabar and Yan (2013) suggested that China's main development challenge are its large distortions and low productivity in services. In contrast, Khor et al. (2015) emphasized that years of schooling are comparatively low in China, which by definition matters particularly for the development of the high-skilled services sector. We will keep an open mind and entertain all three possibilities.

We approach the question why the high-skilled-services sector is underdeveloped in China by building a model of structural change among goods, low-skilled services, and high-skilled services. Our model combines the demand side from Alder et al. (2017) with the production

\footnotetext{
${ }^{1}$ To be precise, these countries-year pairs have GDP per capita falling into the interval of minus $\$ 300$ and plus $\$ 300$ of the GDP per capita that China had in 2011, which is the last year for which we have all required data for China.

${ }^{2}$ We define high-skilled services as the services industries that have a higher share of skilled workers (i.e., workers with at least some college) than the median services industry. These services industries are business and repair services; finance, insurance, and real estate; professional and related services; public administration.
} 
Figure 1: U.S. Sectoral Labor Shares - Census data from IPUMS

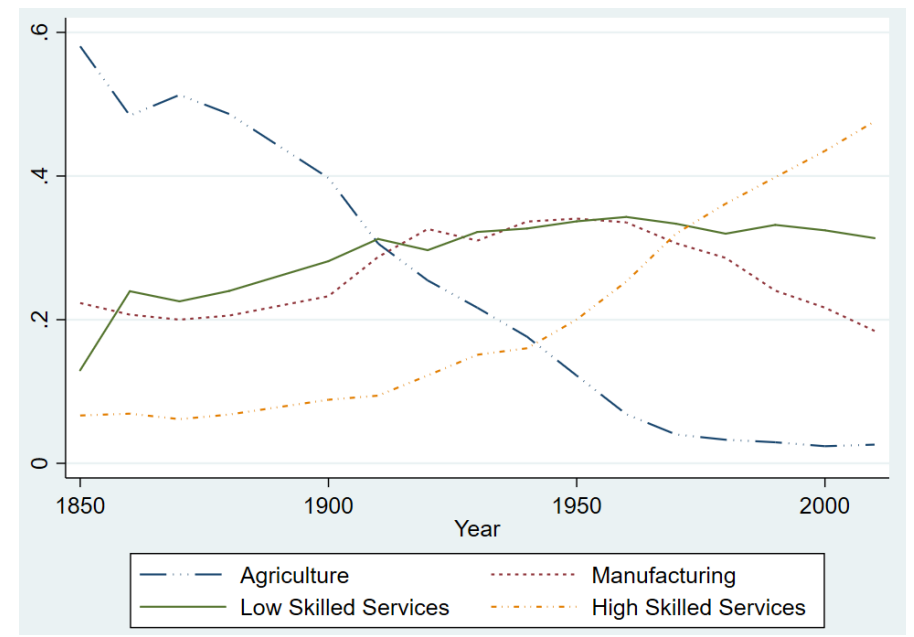

side from Buera et al. (2015). The demand side allows for long-run income effects, which have been found to be important for the development of U.S. services; see for example Boppart (2014) and Comin et al. (2015). The production side allows for skilled and unskilled workers in all sectors, and allows the skill intensities to differ across sectors and to change over time. To capture that in data the nominal labor productivities differ across sectors in China (as is the case in the U.S.), we follow Restuccia et al. (2008) and introduce taxes (they are sometimes also called barriers or wedges) of moving labor among the sectors. They take the form of sectoral labor taxes that increase the sectoral wages and that are lump sum rebated, and they stand in for all distortions that make high-skilled services artificially expensive.

We calibrate our model to match salient features of the Chinese economy since the reforms from 1978. In particular, we match the behavior of sectoral labor, sectoral value added, sectoral relative productivity and prices, and the economy-wide skill premium. We find that this requires large distortions which artificially increase the price of labor and and value added in the high-skilled services sector. We also find that removing these distortions would imply sizeable increases in the employment share of high-skilled services to a similar share as in comparable countries. Moreover, it would imply sizeable increases in GDP per capita and would amplify the effects of technological change and education on GDP per capita in China. These results suggest that distortions in high-skilled services severely hold back the development of the Chinese economy. One possible reason for these distortions is that state-owned enterprises, which have been shown to be much less efficient in China than privately owned enterprises, are more prevalent in the high-skilled service sector than in the other sectors. We document that, indeed, this was the case in terms of employment shares in China in 2016: on average state-owned enterprises employ more than half of the workers in high-skilled services, but fewer than one in twenty of the workers of the other sectors.

Our work is related to several recent papers on the growth performance of the Chinese 
economy. Here, we just mention three prominent examples. Zhu (2012) conducted a growth accounting exercise for China and concluded that TFP growth has been the main driver of GDP growth since the reform in 1978. In contrast to us, he disaggregate the economy into agriculture and non-agriculture and did not analyze the high-skilled service sector. Hsieh and Klenow (2009) found large potential gains in productivity from eliminating the severe misallocation of production factors in Chinese manufacturing. In contrast to them, our focus here is on highskilled services, which are likely to be more important than manufacturing in the second phase of structural change. Song et al. (2011) highlighted that the private sector had higher productivity than the state sector, and that the reallocation of labor from state-owned enterprises to privately owned enterprises led to large aggregate productivity growth. Our work suggests that one reason for the existence of large distortions in high-skilled services is that state-owned enterprises are still much more prevalent there than in the rest of the economy. This is particularly pronounced in education, finance and insurance, and health care.

Our work is also related to several recent papers that argued the usual three-sector split into agriculture, manufacturing, and services is not useful in middle-income and rich countries where most of production is in the service sector. Since productivity growth is heterogenous within the service sector, with some industries showing strong productivity growth while others showing no productivity growth, the effects of reallocation within the service sector are crucial when one seeks to understand the aggregate implications of structural change in these middleincome and rich countries [Baumol et al. (1985), Jorgenson and Timmer (2011), and Buera and Kaboski (2012)]. There are several recent examples that study the implications of this point: Buera et al. (2015) focused on high-skilled versus low-skilled services and the rise of the skill premium, Duarte and Restuccia (2016) focused on market versus non-market services and cross-country differences in productivity, and Duernecker et al. (2017) focused on services with high productivity growth versus services with low productivity growth and Baumol's cost disease.

The remainder of the paper is organized as follows. The next section presents the model. Section 3 connects the model to the Chinese economy and Section 4 presents our results. Section 5 concludes.

\section{Model}

\subsection{Production}

There are three sectors producing goods, low-skilled services, and high-skilled services. We index them by $g, l$, and $h$, respectively. Each of the three sectors are competitive and has a representative firm. There are two types of workers: low-skilled and high-skilled workers, which can move freely across sectors. While production in each sector uses both types of 
workers, the intensity of factor inputs could differ. In each sector, the representative firm uses a CES production function to combine low-skilled and high-skilled workers:

$$
y_{i t}=Z_{i t}\left(\alpha_{i t} h_{i t}^{\frac{\rho-1}{\rho}}+\left(1-\alpha_{i t}\right) \ell_{i t}^{\frac{\rho-1}{\rho}}\right)^{\frac{\rho}{\rho-1}}, \quad i \in\{g, l, h\},
$$

where $y_{i t}, h_{i t}$, and $\ell_{i t}$ are sector $i^{\prime} s$ output, high-skilled and low-skilled labor inputs; $Z_{i t}$ is the total factor productivity of sector $i$, which differs across sectors and time; $\alpha_{i t} \in(0,1)$ captures differences in the intensify of skilled labor across sectors and time; $\rho$ is the elasticity of substitution between the two labor inputs and is assumed to be constant and equal across sectors.

In the data, the nominal labor productivity is different across sectors. In our context, it is important to capture these differences because they will affect overall productivity as well as the sectoral allocation of labor and thus the size of high-skilled service sector. Following Restuccia et al. (2008), we introduce a sector-specific tax $\tau_{i t}$ that gives rise to sectoral differences in labor productivity. Specifically, firms pay an additional amount $\tau_{i t}$ per unit of wage bill and the tax revenue is lump-sum rebated back to the households. ${ }^{3}$ With the tax, the problem of firm $i \in\{g, l, h\}$ is given by:

$$
\max _{y_{i t}, h_{i t}, \ell_{i t}} p_{i t} y_{i t}-\left(1+\tau_{i t}\right)\left(w_{t}^{h} h_{i t}+w_{t}^{l} \ell_{i t}\right) \quad \text { s.t. (1). }
$$

\subsection{Households}

There is a measure one of households. In period $t$, a fraction $\Omega_{t}^{h}$ of the households is high skilled and a fraction $\Omega_{t}^{l}$ is low skilled. Each household is endowed with one unit of time in each period, which the household supplies inelastically to the market.

We use the indirect utility function proposed by Alder et al. (2017). Compared with the Stone-Geary utility, which is commonly used in the literature (see for example Herrendorf et al. (2013)), this indirect utility permits long-run income effects which are a feature of the long-run sectoral consumption expenditure shares. The indirect utility function is a function of prices and income. Let $p_{i t}$ be the price of good $i$ and $\vec{P}_{t} \equiv\left(p_{g t}, p_{l t}, p_{h t}\right)$. Let $e_{t}^{n}$ be the income of a household with skill $n$ and $n=l, h$. The indirect utility function is:

$$
v\left(e_{t}^{n}, \vec{P}_{t}\right)=\frac{1}{\varepsilon}\left(\frac{e_{t}^{n}}{B\left(\vec{P}_{t}\right)}-A\left(\vec{P}_{t}\right)\right)^{\varepsilon}-\frac{1}{\varepsilon}+D\left(\vec{P}_{t}\right),
$$

where $A\left(\vec{P}_{t}\right)$ and $D\left(\vec{P}_{t}\right)$ are homogeneous functions of degree 0 in the price vector and $B\left(\vec{P}_{t}\right)$ is

\footnotetext{
${ }^{3}$ We impose that $\tau_{i t}$ is the same for skilled and unskilled labor, because it is impossible to identify them separately from $\alpha_{i t}$.
} 
a linear homogeneous function:

$$
\begin{aligned}
& A\left(\vec{P}_{t}\right)=\bar{A} \prod_{k \in\{g, l, h\}} p_{k t}^{\mu_{k}-\phi_{k}}, \\
& B\left(\vec{P}_{t}\right)=\prod_{k \in\{g, l, h\}} p_{k t}^{\phi_{k}}, \\
& D\left(\vec{P}_{t}\right)=\bar{D} \sum_{k \in\{l, h\}} v_{k} \frac{1}{\psi_{k}}\left(\frac{p_{k t}}{p_{g t}}\right)^{\psi_{k}} .
\end{aligned}
$$

Let $c_{i t}^{n}$ be the consumption of good $i$ by household $n$. Applying Roy's identity to the indirect utility gives:

$$
c_{i t}^{n}=-\frac{\partial v\left(e_{t}^{n}, \vec{P}_{t}\right) / \partial p_{i t}}{\partial v\left(e_{t}^{n}, \vec{P}_{t}\right) / \partial e_{t}^{n}}
$$

Applying this to (2) gives:

$$
c_{i t}^{n}=-\frac{\left(e_{t}^{n} B_{t}^{-1}-A_{t}\right)^{\varepsilon-1}\left(-e_{t}^{n} B_{t}^{-2} B_{i t}-A_{i t}\right)+D_{i t}}{\left(e_{t}^{n} B_{t}^{-1}-A_{t}\right)^{\varepsilon-1} B_{t}^{-1}}=A_{i t} B_{t}+e_{t}^{n} B_{i t} B_{t}^{-1}-\left(e_{t}^{n} B_{t}^{-1}-A_{t}\right)^{1-\varepsilon} D_{i t} B_{t},
$$

where $A_{i t}, B_{i t}$ and $D_{i t}$ are the derivatives with respect to $p_{i t}$, respectively.

We denote by $E_{t}$ aggregate income of households: $E_{t}=\Omega_{t}^{h} e_{t}^{h}+\Omega_{t}^{l} e_{t}^{l}$. Proposition 3 in Alder et al. (2017) proves that consumption of good $i \in\{g, l, h\}$, and hence its expenditure share, can be aggregated across households and aggregate consumption is a function of $E_{t}$ and prices. ${ }^{4}$ Thus, only the aggregate tax rebate matters for the aggregate consumption. Strictly speaking, the distribution of income, and thus the rebating rule, matters for aggregate demand. However, Proposition 3 in Alder et al. (2017) proved that the distribution effect is summarized by a constant, which turns out to be very close to one in our calibration regardless of the rebating rule. Because we are focused on understanding the sectoral allocation of labor and the resulting effects on GDP growth, it is therefore sufficient to solve for the allocations from the production side given aggregate consumption. Hence, we will define and solve the equilibrium for aggregate consumption and income, implying that we do not need to specify the rebating rule separately for the two types of households.

\subsection{Equilibrium}

Let $s_{i t}\left(\vec{P}_{t}, E_{t}\right)$ be the aggregate consumption expenditure share, $T_{t}$ be the aggregate transfer, $Y_{t} \equiv \sum p_{i t} y_{i t}$ be aggregate value-added, and $e_{i t} \equiv\left(p_{i t} y_{i t}\right) / Y_{t}$ be the share of value-added from

\footnotetext{
${ }^{4}$ The aggregation results from the power utility form of the first term in the indirect utility. Please see the Appendix B for the derivation of the expenditure shares.
} 
sector $i$. The equilibrium is defined as follows:

\section{Equilibrium Definition}

- Given $\vec{P}_{t},\left(y_{i t}, h_{i t}, \ell_{i t}\right)$ solves the problem of the representative firm $i \in\{g, l, h\}$ in period $t$;

- Given $\vec{P}_{t}$ and $E_{t}, s_{i t}\left(\vec{P}_{t}, E_{t}\right)$ are the expenditure shares solved for by Alder et al. (2017);

- Labor markets clear:

$$
\begin{aligned}
& \sum_{i \in\{g, l, h\}} h_{i t}=\Omega_{t}^{h} \\
& \sum_{i \in\{g, l, h\}} \ell_{i t}=\Omega_{t}^{l} ;
\end{aligned}
$$

- Consistency:

$$
\begin{aligned}
E_{t} & =Y_{t}, \\
s_{i t}\left(\vec{P}_{t}, E_{t}\right) & =e_{i t}, \\
T_{t} & =\sum_{i \in\{g, l, h\}} \tau_{i t}\left(w_{t}^{h} h_{i t}+w_{t}^{l} \ell_{i t}\right) .
\end{aligned}
$$

\subsection{The Role of $\tau_{i t}$}

The details of the solution of the model are given in Appendix B. In this subsection, we briefly discuss the effect of $\tau_{i t}$ on the labor allocation. Taking the ratio between the first-order conditions for $h_{i t}$ and $\ell_{i t}$ gives:

$$
\frac{h_{i t}}{\ell_{i t}}=\left(\frac{\alpha_{i t}}{1-\alpha_{i t}}\right)^{\rho}\left(\frac{w_{t}^{l}}{w_{t}^{h}}\right)^{\rho} .
$$

Define $a_{i t} \equiv \alpha_{i t} /\left(1-\alpha_{i t}\right)$ and $\hat{w}_{t} \equiv w_{t}^{h} / w_{t}^{l}$. The above ratio becomes:

$$
\frac{h_{i t}}{\ell_{i t}}=a_{i t}^{\rho} \hat{w}_{t}^{-\rho}
$$

Hence the production function can be written as:

$$
y_{i t}=Z_{i t}\left(1-\alpha_{i t}\right)^{\frac{\rho}{\rho-1}}\left(a_{i t}^{\rho} \hat{w}_{t}^{1-\rho}+1\right)^{\frac{\rho}{\rho-1}} \ell_{i t} .
$$


Define $\varphi_{i t}\left(\hat{w}_{t}\right) \equiv\left(1-\alpha_{i t}\right)^{\frac{\rho}{\rho-1}}\left(a_{i t}^{\rho} \hat{w}_{t}^{1-\rho}+1\right)^{\frac{\rho}{\rho-1}} \cdot y_{i t}$ can be further rewritten as $y_{i t}=Z_{i t} L_{i t}=$ $Z_{i t} \varphi_{i t}\left(\hat{w}_{t}\right) \ell_{i t}$. Using this relation and the first-order conditions, we can derive:

$$
\frac{p_{i t} y_{i t}}{p_{j t} y_{j t}}=\left(\frac{1+\tau_{i t}}{1+\tau_{j t}}\right)\left(\frac{1-\alpha_{j t}}{1-\alpha_{i t}}\right)\left(\frac{\varphi_{j t}\left(\hat{w}_{t}\right)}{\varphi_{i t}\left(\hat{w}_{t}\right)}\right)^{\frac{1-\rho}{\rho}}\left(\frac{\ell_{i t}}{\ell_{j t}}\right)
$$

We can solve out $\frac{\ell_{i t}}{\ell_{j t}}$ :

$$
\frac{\ell_{i t}}{\ell_{j t}}=\left(\frac{1+\tau_{j t}}{1+\tau_{i t}}\right)\left(\frac{1-\alpha_{i t}}{1-\alpha_{j t}}\right)\left(\frac{\varphi_{i t}\left(\hat{w}_{t}\right)}{\varphi_{j t}\left(\hat{w}_{t}\right)}\right)^{\frac{1-\rho}{\rho}}\left(\frac{p_{i t} y_{i t}}{p_{j t} y_{j t}}\right) .
$$

Let $n_{i t}=h_{i t}+\ell_{i t}$ be the total labor inputs of sector $i$. Combining equations (10) and (13) gives the ratio between $n_{i t}$ and $n_{j t}$ :

$$
\frac{n_{i t}}{n_{j t}}=\left(\frac{1+\tau_{j t}}{1+\tau_{i t}}\right)\left(\frac{1-\alpha_{i t}}{1-\alpha_{j t}}\right)\left(\frac{\varphi_{i t}\left(\hat{w}_{t}\right)}{\varphi_{j t}\left(\hat{w}_{t}\right)}\right)^{\frac{1-\rho}{\rho}}\left(\frac{p_{i t} y_{i t}}{p_{j t} y_{j t}}\right)\left(\frac{1+a_{i t}^{\rho} \hat{w}_{t}^{-\rho}}{1+a_{j t}^{\rho} \hat{w}_{t}^{-\rho}}\right)
$$

Equation (14) implies that the sectoral employment ratio is inversely related with the sectoral taxes. We can rewrite equation (14) as the ratio between relative nominal sectoral labor productivities:

$$
\frac{p_{j t} y_{j t} / n_{j t}}{p_{i t} y_{i t} / n_{i t}}=\left(\frac{1+\tau_{j t}}{1+\tau_{i t}}\right)\left(\frac{1-\alpha_{i t}}{1-\alpha_{j t}}\right)\left(\frac{\varphi_{i t}\left(\hat{w}_{t}\right)}{\varphi_{j t}\left(\hat{w}_{t}\right)}\right)^{\frac{1-\rho}{\rho}}\left(\frac{1+a_{i t}^{\rho} \hat{w}_{t}^{-\rho}}{1+a_{j t}^{\rho} \hat{w}_{t}^{-\rho}}\right) .
$$

Equation (15) shows that the relative taxes drive a wedge between the nominal sectoral labor productivity. This will allow us to match differences in sectoral labor productivities in the data.

\section{Calibration}

This section first classifies workers and services industries into high-skilled and low-skilled services and then lays out the calibration strategy and the construction of the data targets. The details of the calibration and construction of the data are provided in the Appendix.

\subsection{Definition of Sectors}

We link skills with education in the data. Low-skilled workers do not have a college education and high-skilled workers have at least some college. Because this paper focuses on the structural change within services, we do not separate agriculture and manufacturing. Instead, we group agriculture, mining, construction, and manufacturing together as the goods sector. Using the IPUMS Census data, we classify service industries into high-skilled and low-skilled based on the fraction of high-skilled workers in an industry. Low-skilled services industries 
are the industries that have a smaller fraction of high-skilled workers than the median services industries. The low-skilled services sector comprises personal services; transportation and communication; utilities; wholesale and retail trade. High-skilled services industries are the remaining services industries. The high-skilled services industries comprises business and repair services; finance, insurance, and real estate; professional and related services (mainly education and health care); public administration. As shown in the Appendix A, the assignment to low-skilled and high-skilled services is robust for all census years after the post-war period. ${ }^{5}$

\subsection{Calibration Strategy}

We calibrate the model to match salient features of the Chinese Economy. Because aggregate income and prices are the inputs in the indirect utility and have to be consistent with outcomes from firms' problems, we choose to target them also in the calibration. The advantage of doing so is that it allows us to separate the calibration of the production parameters from the calibration of the preference parameters while still assuring that the consistency conditions in the equilibrium definition hold. This strategy avoids having to estimate the preference parameters numerous times until the implied parameters are consistent with the production side.

Following Alder et al. (2017), we estimate the preference parameters using annual data on income, prices and sectoral expenditure shares. We link aggregate income $E_{t}$ in the model to nominal value-added GDP per worker in the data, $p_{i t}$ to prices of sectoral value added, and $s_{i t}$ to sectoral value-added shares. The estimated preferences give $s_{i t}\left(\vec{P}_{t}, E_{t}\right)$ for any combination of sectoral prices and aggregate income.

The calibration of the production parameters combines the strategies in Buera et al. (2015) and Duernecker et al. (2017). Following Katz and Murphy (1992), we set the elasticity of substitution between high and low-skilled labor $\rho$ to be 1.42. Because only the relative taxes matter for the equilibrium, we normalize $\tau_{g t}=0$ for every year. The rest of the parameters $\left\{\alpha_{i t}, Z_{i t}\right\}_{i=g, l, h},\left\{\tau_{i t}\right\}_{i=l, h}$, and $\left\{\Omega_{t}^{h} / \Omega_{t}^{l}\right\}$ can be calibrated period by period. Taking $p_{g t}$ from the data, we calibrate those nine parameters every period jointly to match nine targets: the three ratios between high and low-skilled workers by sector $h_{i t} / \ell_{i t}$, the two relative sectoral nominal productivity $\left(p_{i t} y_{i t} / n_{i t}\right) /\left(p_{g t} y_{g t} / n_{g t}\right)$, the two relative sectoral prices $p_{i t} / p_{g t}$, the nominal GDP $Y_{t}$, and the economy-wide skill premium $\hat{w}_{t}{ }^{6}$

We next briefly discuss the identification of the parameters. Given the skill premium, equation (10) implies that $\alpha_{i t}$ can be pinned down by sector $i^{\prime} s$ high-skilled-to-low-skilled labor ratio. Equation (15) implies that $\tau_{i t}$ can be pinned down by the relative nominal sectoral labor

\footnotetext{
${ }^{5}$ The IPUMS 2010 Census sample does not have industry information. The numbers reported for 2010 are constructed from IPUMS 2010 American Community Survey.

${ }^{6}$ One price can always be normalized. We choose to set $p_{g t}$ to the data value instead of one because we target the nominal GDP.
} 
productivity. $Z_{i t}$ affects relative prices and GDP and therefore is pinned down by relative prices and nominal GDP. $\Omega_{t}^{h} / \Omega_{t}^{l}$ is pinned down by the skill premium.

\subsection{Data Targets}

We borrow the data on the Chinese skill premium from Meng (2012), who estimated it during 1988-2009 using a Mincer wage regression. We use the GGDC 10-sector database to construct the sector-level variables for China from 1952-2009. ${ }^{7}$ Following Duernecker et al. (2017), we aggregate industry-level variables to construct sector-level employment, output, prices, nominal and real labor productivities. Unfortunately, the 10-sector database does not contain data on the numbers of worker by industry and by education. To overcome this problem, we use the Chinese Household Income Project (CHIP), which is a cross-sectional household survey that separately surveyed every 5-7 years rural, urban and migrant households during 1988-2013. ${ }^{8}$

We construct the ratio between high and low-skilled workers by sector for the years for which the CHIP data is available. We then linearly interpolate the sectoral ratios to get the ratios between high and low-skilled workers for the years for which CHIP data is not available. The employment by sector and by education is obtained by combining the ratios calculated from CHIP and the total employment by sector in the 10-sector database. As shown in the Appendix D, the resulting share of high-skilled in the workforce is broadly consistent with that reported by the National Bureau of Statistics.

One of the counterfactuals of the next section requires parameters from the U.S. economy for comparison. To calibrate the model to the U.S. economy, we use data targets from World Klems during 1947-2010. We use the 2003 release since it includes data on the number of workers by education and industry. We estimate the skill premium from the Current Population Survey (CPS) using a Mincer wage regression similar to that of Meng (2012).

\subsection{Calibration Results}

The calibrated parameters from the production side for China are reported in Figure 2. The overall ratio of high-skilled to low-skilled workers $\Omega_{t}^{h} / \Omega_{t}^{l}$ has increased from $3 \%$ to $13 \%$. Although not targeted, Figure 2 shows that the calibrated $\Omega_{t}^{h} / \Omega_{t}^{l}$ is very close to the data. The skill intensity $\alpha_{i t}$ also increased significantly in each sector. Sectoral TFP $Z_{i t}$ increased by factors of 8.7, 3.3, and 5.6 in goods, low-skilled services, and high-skilled services, respectively. The tax rate $\tau_{i t}$ has declined from 0.83 to 0 in the low-skilled services. In contrast, the tax rate in high-skilled services has fluctuated around the large mean of 2.5 without showing a clear trend.

\footnotetext{
${ }^{7}$ The industry classification in the 10-sector data is fairly similar to the classification in the Census Data. Highskilled services are Finance, insurance, real estate and business services and Government services. Government services includes professional services and public administration.

${ }^{8}$ The migrant survey starts in 2002.
} 
Figure 2: Calibrated Parameters - Production Side
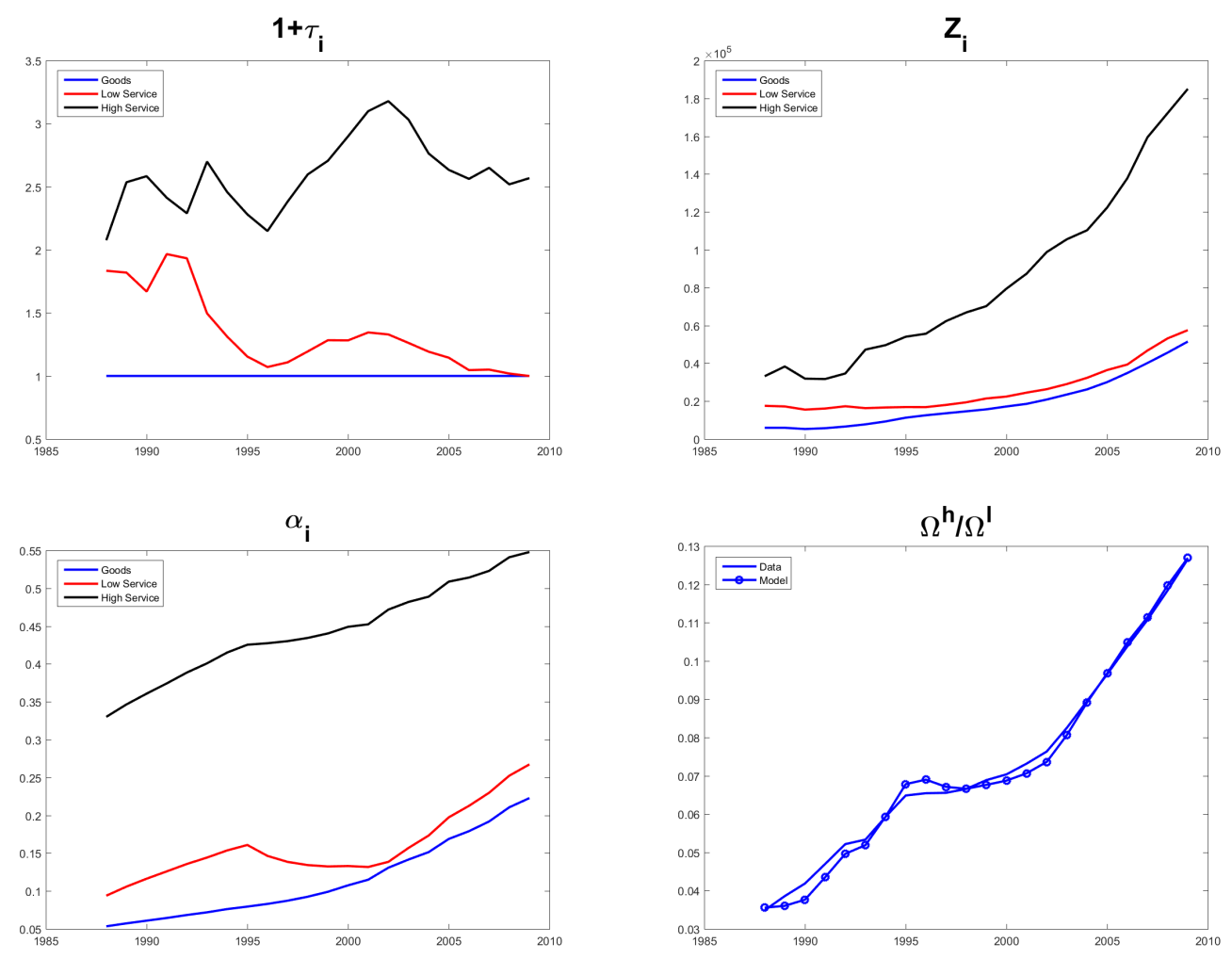

The calibrated model matches the Chinese targets well. ${ }^{9}$ In fact, as shown in Figure 3, the calibrated model for China matches exactly nominal value-added per worker, relative prices, skill premium, relative nominal labor productivity, and the high-to-low-skilled ratio by sector. The calibrated utility also matches the expenditure shares well. ${ }^{10}$ Lastly, the calibrated model gets close to several non-targeted moments, including sectoral, real labor productivity and the sectoral employment shares; see Figure 4.

\section{Results}

This section studies the effects of TFP, skill composition, and barriers to moving across sectors on the past, current, and future growth of the Chinese economy. We first use our model to identify the contribution of different factors on the Chinese growth miracle during the past three decades. We then identify which factor led to the underdevelopment of the high-skilled services sector in China. Lastly, we analyze the Chinese growth potential for the future by eliminating the barriers to moving across sectors, in particular, into high-skilled services. Real value-added is measured by 2009 prices throughout this section, because we don't have international prices

\footnotetext{
${ }^{9}$ The model also matches the targets for the U.S. well.

${ }^{10}$ The calibrated preference parameters are reported in the Appendix.
} 
Figure 3: Targeted Variables - Model and Data
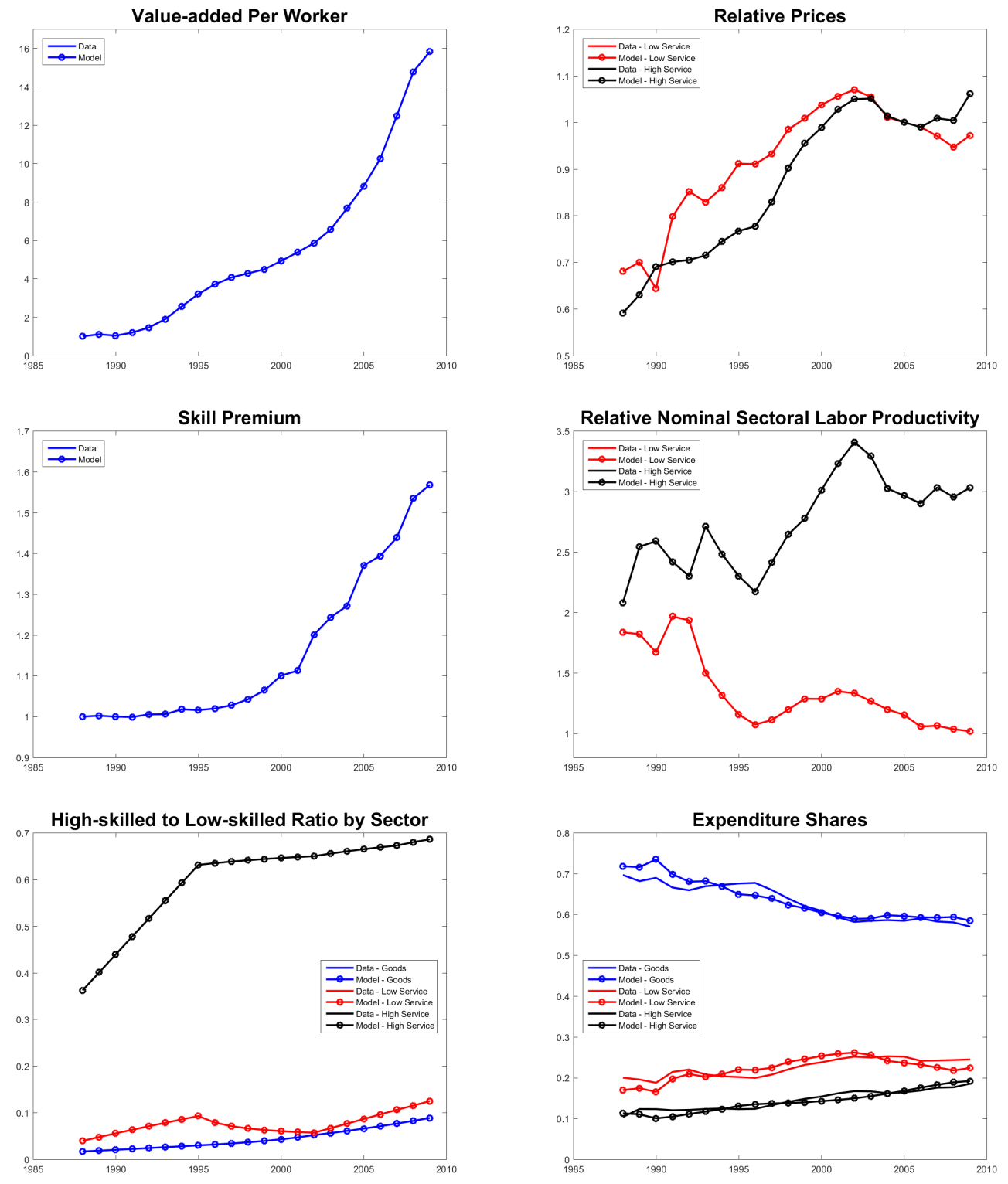

Figure 4: Not Targeted Variables - Model and Data
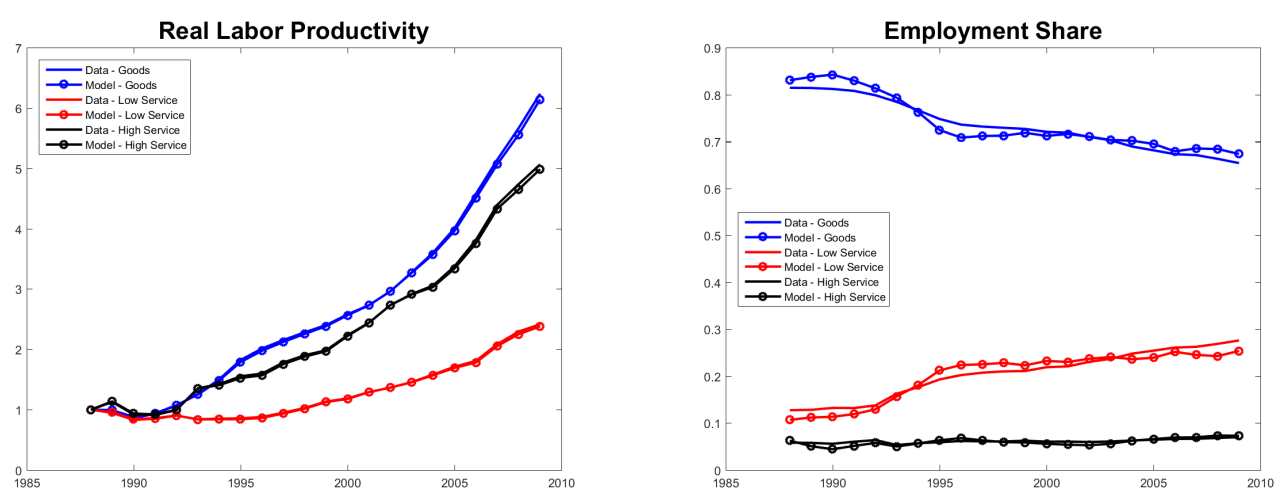
Figure 5: Counterfactual 1: Constant $Z_{i t}$
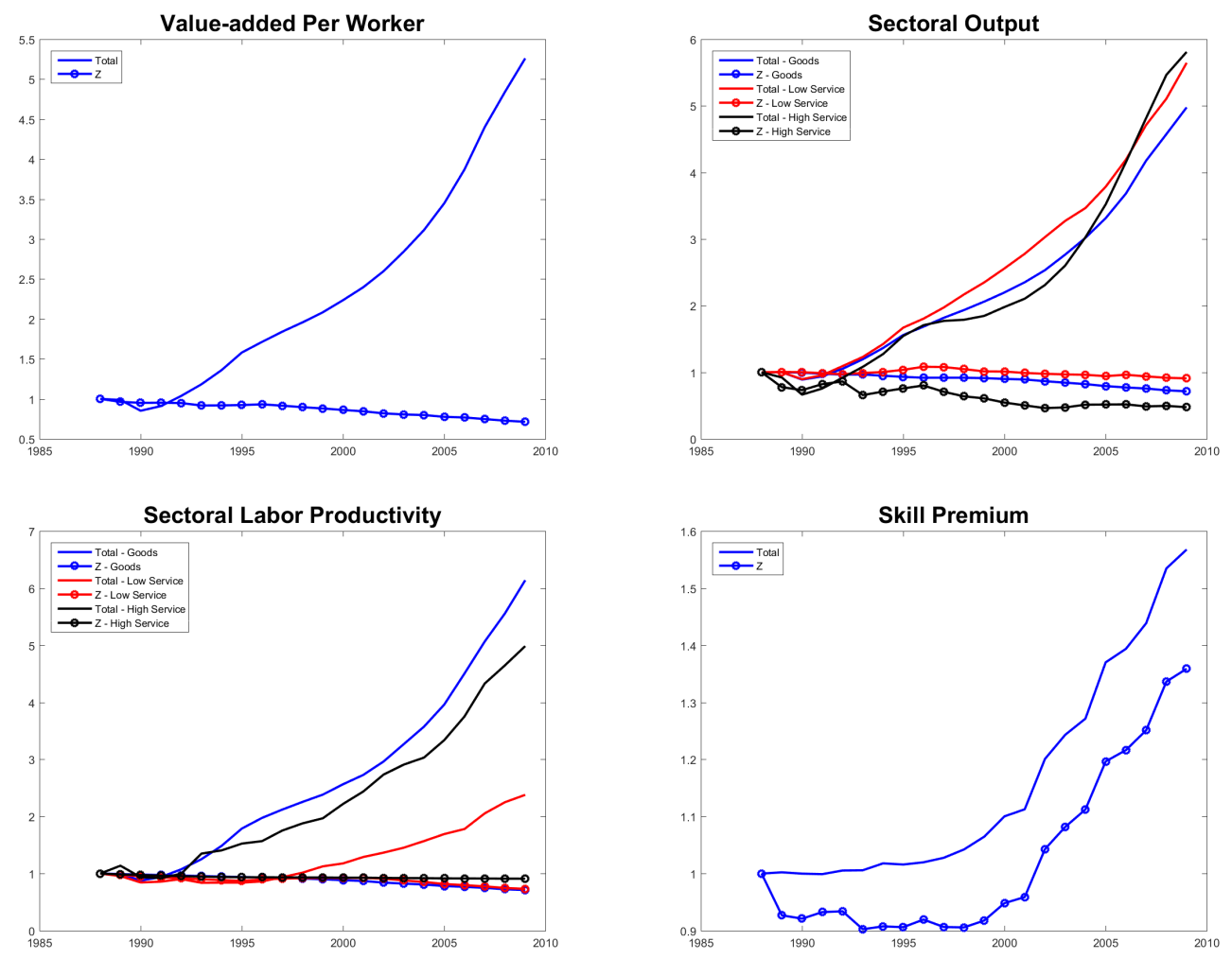

for China.

\subsection{Drivers of Growth during 1988-2009}

This subsection uses the calibrated model to identify the contributions of different factors to Chinese GDP growth during 1988-2009. To achieve this, we keep one of the factors constant at its 1988 value and let the other factors change as dictated by the calibration. This exercise makes sense only for factors which actually do have trend growth, namely, $Z_{i t}, \Omega_{t}^{h}$, and $\alpha_{i t}$, but not for factors which don't, namely, $\tau_{i t}$.

Figure 5 reports the results of holding $Z_{i t}$ constant at its 1988 value. As a comparison, the figure also reports the results when all factors change as dictated by the calibration. The difference between the two lines is the contribution of TFP growth to development in China. Similarly, Figure 6 and 7 report the effects of keeping constant the share of skilled labor or keeping constant the skill intensity. Clearly, the growth of TFP is the main driver of the Chinese growth miracle since 1980s. Without TFP growth, sectoral labor productivity and outputs as well as real value added per worker would actually have declined, and the growth of the skill premium would have been considerably smaller.

The increase in the fraction of high-skilled labor also contributes to the growth in the real value-added per worker, but the contribution is much smaller than that of TFP. However, the 
Figure 6: Counterfactual 2: Constant $\mathbf{\Omega}^{h}$
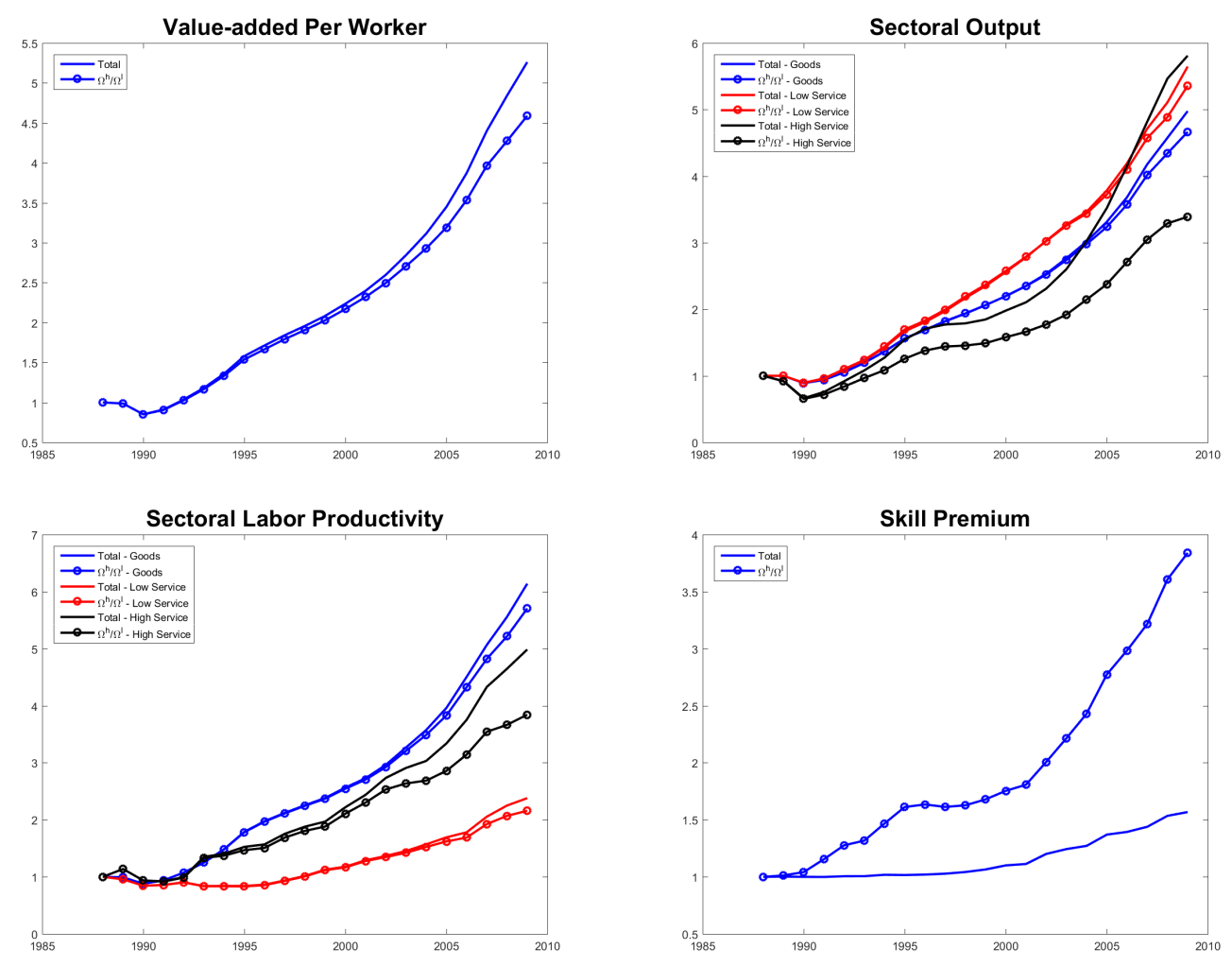

increase in high-skilled labor has a tremendous effect on the growth of high-skilled services. Without the increase in high-skilled labor, labor productivity of high-skilled services would have increased by only a factor of 3.8 instead of the factor 5 that it did increase, and output of high-skilled services would have increased by only a factor of 3.4 instead of the factor 5.8 that it did increase. Because high-skilled services amount to less than $15 \%$ of the total real value added over this period, the huge increase in the output of high-skilled services does not translate into a comparable increase in the real value added per worker. As in Katz and Murphy (1992), the growth of $\alpha_{i t}$ drives up the demand for high-skilled labor. Without the increase in the supply of skilled labor, the skill premium would have been much higher.

The results on the contribution of TFP and education on the economic growth in China are consistent with those of Zhu (2012). Doing a growth accounting exercise, he also finds that TFP growth is the main driver of China's rapid growth since 1978 whereas he contribution of human capital is positive yet modest.

In sharp contrast to the previous results, the increase in the skill intensity $\alpha_{i t}$ actually leads to a decline in the real value-added per worker. This is surprising only at first sight. Upon closer inspection, one realizes that during the period of investigation the share of high-skilled services stays rather low, increasing from only $3 \%$ at the beginning to a little over $10 \%$ at the end of the period. This means that there is relative scarcity of high-skilled labor, and so the 
Figure 7: Counterfactual 3: Constant $\alpha_{i t}$
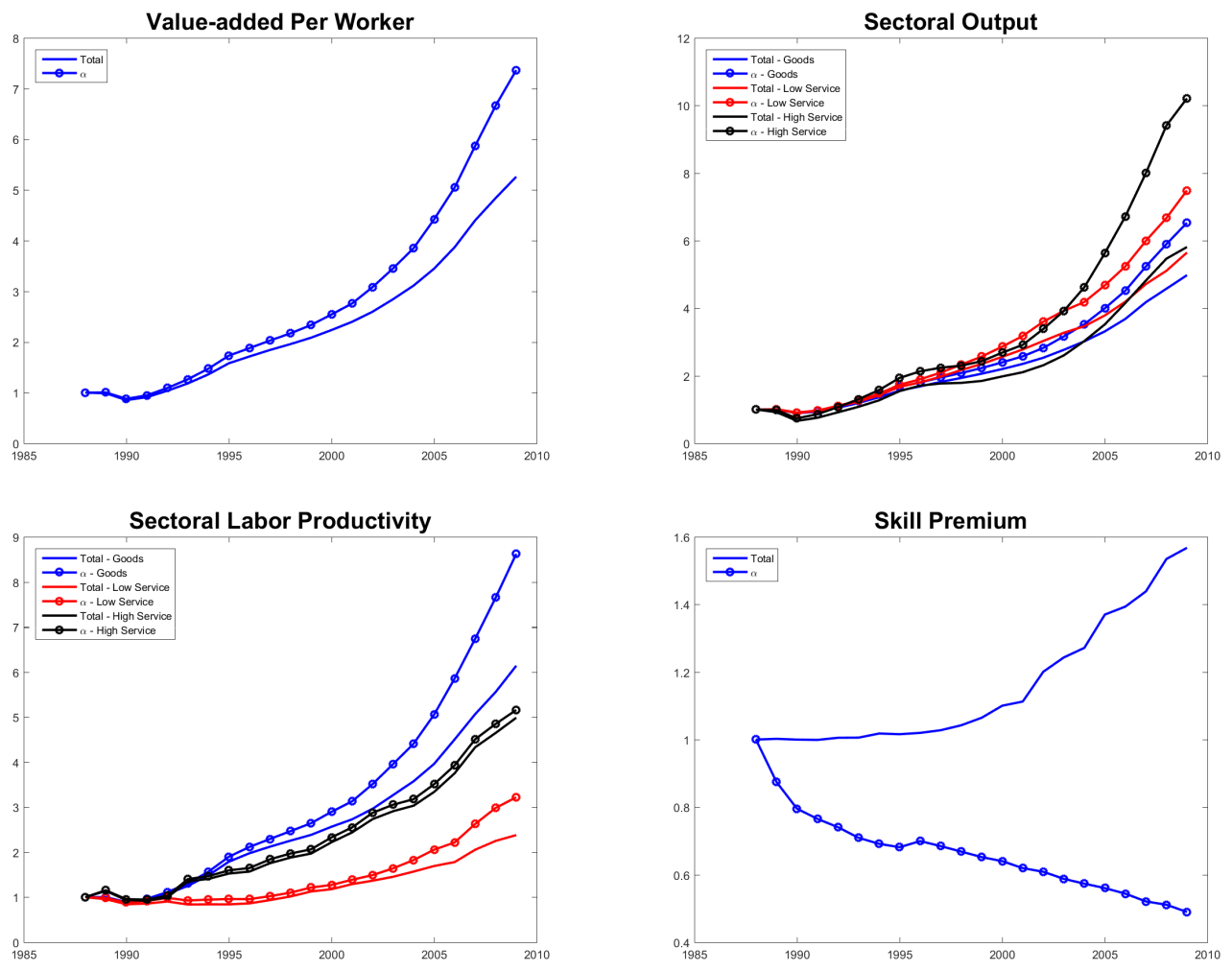

sectoral value added would actually increase if the relative weights of high-skilled labor stayed the same, instead of increased. Note that without increases in the skill intensity, the demand for high-skilled labor would not have been increased, implying that the increase in the supply of high-skilled labor would have led to a decline in the skill premium.

\subsection{Causes for the Under-development of High-skilled Services}

This subsection explores why the high-skilled services sector is under developed in China. We study three possible reasons: large barriers to moving into high-skilled services (i.e., high $\tau_{h t}$ ), low sectoral TFP (i.e., low $Z_{h t}$ ), or low numbers of skilled workers (i.e., low $\Omega_{t}^{h} / \Omega_{l}^{t}$ ). We start by investigating which of these parameters differs considerably from the value that it assumes in a comparable country. To answer this question, we would ideally identify the year in which GDP per capita of the United States was comparable with that of China today and then report what $\tau_{h t}, Z_{h t}$, and $\Omega_{t}^{h} / \Omega_{l}^{t}$ were for the U.S. in that year. Unfortunately, this approach is not feasible for two reasons. First, as pointed out by Duarte and Restuccia (2010), the lack of reliable sectoral data on purchasing power parity makes it meaningless to compare sectoral TFP levels across countries. This is a more grave problem with non-homothetic preferences, because the level of TFP plays an important role for the allocation of labor. Second, in 2009, the last year for which we have all Chinese data, China was still much poorer than the U.S. was in the first year for 
which we have comparable data. ${ }^{11}$

Table 2: Actual and Counterfactual Parameters

\begin{tabular}{lccc}
\hline Parameters & $\mathrm{g}$ & $\mathrm{l}$ & $\mathrm{h}$ \\
\hline$Z_{i, 09} / Z_{i, \text { count }}$ & 2.06 & 3.66 & 0.44 \\
$\left(1+\tau_{i, 09}\right) /\left(1+\tau_{i, \text { count }}\right)$ & 1.00 & 1.23 & 3.19 \\
\hline
\end{tabular}

" 09 " is for China 2009 and "count" is for counterfactual. $g, l$, and $h$ stand for goods, lowskilled services, and high-skilled services.

As an alternative, we therefore take as the benchmark the year in which GDP per capita of the U.S. was twice as large as that of China in 2009, that is, the year 1962, and then ask what it would take for China to be similar to the U.S. in 1962. We start with the parameters that are directly observable. In particular, $\Omega_{h} / \Omega_{l}$ is 0.26 for the U.S. in 1962 and is 0.13 for China in 2009, so below we will explore a doubling of the ratio of high-skilled to low-skilled workers. $\left(\alpha_{g}, \alpha_{l}, \alpha_{h}\right)$ is $(0.26,0.30,0.49)$ for the U.S. in 1962 and is $(0.22,0.27,0.55)$ for China in 2009. Since these numbers are fairly close, we won't further pursue the role of $\alpha_{i}$. This leads us to the sectoral TFPs and sectoral barriers that are not directly observed but potentially crucial in this context. To get a handle on them, we ask the calibrated model what sectoral TFPs and what sectoral barriers would China need to double its real GDP while reaching the sectoral composition of the U.S. in 1962. Given the calibrated Chinese preferences, we set $\alpha_{i}$ and $\Omega_{h} / \Omega_{l}$ to the U.S. values in 1962 and find $Z_{i}$ and $\tau_{i}$ such that Chinese real GDP (i.e., real value added) is twice as much as that in 2009 while the Chinese sectoral employment and expenditure shares are the same as the U.S. in $1962 .^{12}$

Table 2 compares the $Z_{i}$ and $\tau_{i}$ from the counterfactual experiment and the calibrated values in 2009 for China. The two sets of values differ dramatically. In comparison to the counterfactual, China in 2009 is more than twice as productive in goods, more than three times as productive in low-skilled services, but less than half as productive in high-skilled services. In terms of barriers, China in 2009 is slightly more distorted in low-skilled services while is more than three times as distorted in high-skilled services. Below, we will therefore explore what happens when we divide the TFPs in goods by two and in low-skilled services by three, double the TFP in high-skilled services, and set $\tau_{h}=0$.

Table 3 confirms that the barriers to moving into high-skilled services are the main reason for why employment in high-skilled services is so low. In particular, if we eliminate just the barriers of moving into high-skilled services (third row with $\tau_{g, 09}, \tau_{l, 09}, \tau_{h}=0$ ), then employment in high-skilled services rises to $19 \%$, which is two percentage points higher than the average

\footnotetext{
${ }^{11}$ From the Penn World Tables 8.1, GDP per capita of the U.S. in 1950 was $60 \%$ higher than GDP per capita of China was in 2009.

${ }^{12}$ Since we don't have international prices for sectoral value added, we use Chinese constant prices from 2009 to calculate Chinese real GDP. While that is not ideal, it's defensible.
} 
Table 3: Determinants of the Size of the High-Skilled Services Sector

\begin{tabular}{lccc}
\hline & $Y$ & $s_{h}$ & $n_{h}$ \\
\hline 2009 Benchmark Calibration & 1 & 0.19 & 0.07 \\
$\tau_{g, 09}, \tau_{l, 09}, \tau_{h}=0$ & 1.17 & 0.23 & 0.19 \\
$Z_{g}=Z_{g, 09} / 2, Z_{l}=Z_{l, 09} / 3, Z_{h}=2 Z_{h, 09}$ & 0.78 & 0.22 & 0.09 \\
$Z_{g}=Z_{g, 09}, Z_{l}=Z_{l, 09}, Z_{h}=2 Z_{h, 09}$ & 1.26 & 0.23 & 0.09 \\
$\Omega^{h} / \Omega^{l}=2 \Omega_{09}^{h} / \Omega_{09}^{l}$ & 1.06 & 0.21 & 0.10 \\
\hline
\end{tabular}

$Y$ is aggregate real value added, $s_{h}$ is the expenditure share of high-skilled services, and $n_{h}$ is the employment share of high-skilled services. The index 09 is for Chinese parameters of the benchmark calibration.

over the comparable countries listed in Table 1 from the introduction. So just removing barriers moving into the high-skilled services sector would increase the employment share to more than that of comparable countries. In contrast, if we dramatically increase the TFP of high-skilled services (fourth and fifth row) or dramatically increase the share of skilled workers (sixth row), then the share of high-skilled employment increases only a few percentage points.

Table 4: Share of Employment in State-Owned Enterprises in China in 2016 (in percent, National Bureau of Statistics)

\begin{tabular}{lr}
\hline Goods & $\mathbf{1 . 7}$ \\
\hline Agriculture, Forestry, Fishing & 1.1 \\
Manufacturing & 1.5 \\
Construction & 4.4 \\
Mining & 9.0 \\
\hline Low-Skilled Services & $\mathbf{4 . 0}$ \\
\hline Wholesale and Retail & 0.6 \\
Household Services & 1.2 \\
Hotels and Restaurants & 1.4 \\
Transport and Post & 24.0 \\
Utilities & 45.0 \\
\hline High-Skilled Services & $\mathbf{5 1 . 5}$ \\
\hline Leasing and Business Service & 4.0 \\
Real Estate & 7.4 \\
Information Technology & 9.2 \\
Finance and Insurance & 22.0 \\
Scientific Research and Technical Services & 51.0 \\
Health Care & 87.0 \\
Education & 92.0 \\
Public Administration & 99.0 \\
\hline
\end{tabular}

The previous results raise the question what nature the barriers/distortions in high-skilled services take. One possible distortion in high-skilled services is that state-owned enterprises, which are usually thought to be less efficient, are more prevalent in the high-skilled service sector than in the other sectors. It is well known that, on average, state-owned enterprises are 
more distorted and less productive than privately owned ones; see, for example, the discussion in Song et al. (2011). Table 4 shows that, indeed, the employment share of state-owned enterprised tends to be much larger in high-skilled services than in the other sectors. In particular, state-owned enterprises employ more than half of the workers in high-skilled services, but less than one in twenty five of the workers in the other sectors.

\subsection{Future Growth}

Having established that barriers to moving into high-skilled services are the primary reason for the underdevelopment of high-skilled services in China, this subsection studies the quantitative effects of removing them. We perform four counterfactual experiments. The first experiment analyses the effect of removing the barriers on real value added and the size of the high-skilled services sector. The second and third experiments analyze the interaction effects between barriers and TFP. The last experiment analyzes the interaction effect between barriers and education. The benchmark is the calibrated 2009 Chinese economy.

The first row of Table 5 reports the results of removing the barriers from the benchmark economy. Columns 7-9 report aggregate real value added, expenditure shares and employment shares of high-skilled services after removing the barriers. As a comparison, columns 4-6 report the values for the same variables in the benchmark economy where aggregate real value added normalized to one. The table shows that removing the barriers alone leads to an increase in aggregate real value-added by $17 \%$ and increases the expenditure share of high-skilled services, which is the same as the share of nominal value added, from $19 \%$ to $23 \%$. The increases come from the reallocation of labor from goods and low-skilled services to high-skilled services. Consequently, the employment share in high-skilled services increases from $7 \%$ to $19 \%$.

The rest of Table 5 analyzes the interaction between removing the barriers and growing TFP. The third row reports the results from the experiment of having TFP $Z_{i}$ grow by its average sectoral growth rate over the 2000s for one year and the fourth row reports similar results while having TFP grow at the same rate for ten years. With the barriers, the growth of TFP leads to comparable growth in aggregate real value added and higher expenditure share of high-skilled services. The reallocation of labor between sectors is rather limited. In contrast, without the barriers, the growth of TFP leads to $17 \%$ larger growth in aggregate real value added than TFP growth alone. This implies that removing the barriers amplifies the growth effect of TFP in a quantitatively sizeable way.

Because high-skilled services are underdeveloped in China, it is also of interest to analyze the interaction between removing the barriers and growing TFP only in the high-skilled service sector. Table 6 reports the results of this experiment. The third and fourth rows report the results of growing TFP in the high-skilled services by its average growth rate in the 2000s for one and ten years, respectively. As in the experiments with TFP growth in all sectors, removing 
Table 5: Interaction between $\tau_{i}$ and $Z_{i}$

\begin{tabular}{lcc|ccc|ccc}
\hline & & & \multicolumn{4}{|c|}{$\tau_{i, 09}$} & \multicolumn{3}{|c}{$\tau_{i}=0$} \\
$Z_{g}$ & $Z_{l}$ & $Z_{h}$ & $Y$ & $s_{h}$ & $n_{h}$ & $Y$ & $s_{h}$ & $n_{h}$ \\
\hline 1 & 1 & 1 & 1 & 0.19 & 0.07 & 1.17 & 0.23 & 0.19 \\
1.10 & 1.08 & 1.09 & 1.10 & 0.20 & 0.08 & 1.29 & 0.24 & 0.20 \\
2.69 & 2.26 & 2.41 & 2.60 & 0.25 & 0.10 & 3.04 & 0.29 & 0.24 \\
\hline
\end{tabular}

$Y$ is aggregate real value added, $s_{h}$ is the expenditure share of high-skilled services, and $n_{h}$ is the employment share of high-skilled services. $\tau_{i, 09}$ refers to the calibrated values in 2009 and $\tau_{i}=0$ refers to no barriers. The first three columns report the $Z_{i}$ used for the experiments relative to the benchmark $Z_{i}$ in 2009. The third and fourth rows assume $Z_{i}$ grows at the average growth factor of TFP in the 2000s for one year and for ten years.

the barriers amplifies the growth effect of TFP and the amplification effect is even stronger, with the increase in the growth factor by $20 \%$ for one year of growth and by $47 \%$ for ten years of growth in TFP. Moreover, comparing Tables 5 and 6 suggests that the contribution of TFP growth in the high-skilled services to aggregate growth is much larger when its barrier is removed. This is not surprising, because as shown in Figure 2, in 2009 barriers are by far the largest in the high-skilled services, implying that the amplification mainly comes from the effect of removing barriers to moving into the high-skilled services.

Table 6: Interaction between $\tau_{h}$ and $Z_{h}$

\begin{tabular}{lll|lll|lll}
\hline & & & \multicolumn{3}{|c|}{$\tau_{i, 09}$} & \multicolumn{3}{|c}{$\tau_{g, 09}, \tau_{l, 09}, \tau_{h}=0$} \\
$Z_{g}$ & $Z_{l}$ & $Z_{h}$ & $Y$ & $s_{h}$ & $n_{h}$ & $Y$ & $s_{h}$ & $n_{h}$ \\
\hline 1 & 1 & 1 & 1 & 0.19 & 0.07 & 1.17 & 0.23 & 0.19 \\
1 & 1 & 1.09 & 1.02 & 0.20 & 0.08 & 1.22 & 0.24 & 0.20 \\
1 & 1 & 2.41 & 1.38 & 0.24 & 0.09 & 2.03 & 0.28 & 0.23 \\
\hline
\end{tabular}

\footnotetext{
$Y$ is aggregate real value added, $s_{h}$ is the expenditure share of high-skilled services, and $n_{h}$ is the employment share of high-skilled services. $\tau_{i, 09}$ refers to the experiments of setting $\tau_{i}$ to the calibrated values in 2009 and $\left(\tau_{g, 09}, \tau_{l, 09}, \tau_{h}=0\right)$ refers to the experiments of only removing the barriers in the high-skilled service sector. The first three columns report the $Z_{i}$ used for the experiments relative to the benchmark $Z_{i}$ in 2009. The third and fourth rows assume $Z_{h}$ grows at its average growth factor in the 2000s for one year and for ten years.
}

Lastly, we turn to the interaction between barriers and education. The first row of Table 7 reports the benchmark economy in which the share of high-skilled labor $\Omega^{h}$ is $11 \%$. The second and third rows report the experiments of increasing $\Omega^{h}$ to $15 \%$ and $20 \%$. As expected, increasing the share of high-skilled labor leads to higher aggregate real value-added. Consistent with the previous experiments, removing barriers leads to much higher growth and the effect again comes from the reallocation of labor into high-skilled services. More importantly, the effects on GDP growth of removing the barriers increases with the share of high-skilled labor: the growth factor increases by $17 \%, 19 \%$, and $23 \%$ for $\Omega^{h}$ equal to $0.11,0.15$, and 0.20 , respectively. This implies that when the workforce becomes more educated, the gain of removing the barriers is 
even higher.

To summarize, this section first has established that TFP was the main driver of the economic growth in China in the past 30 years. It then has identified large barriers of moving into high-skilled services to be the main cause of the under-development of high-skilled services in China. Lastly, it has shown that removing the barriers leads to sizeable gains in Chinese GDP growth; taking as given the future growth in TFP and in education, removing the barriers amplifies their growth and leads to even higher GDP growth.

Table 7: Interaction between $\tau_{i}$ and $\mathbf{\Omega}^{h}$

\begin{tabular}{l|lll|lll}
\hline & & $\tau_{i, 09}$ & \multicolumn{3}{|c}{$\tau_{i}=0$} \\
$\Omega^{h}$ & $Y$ & $s_{h}$ & $n_{h}$ & $Y$ & $s_{h}$ & $n_{h}$ \\
\hline 0.11 & 1 & 0.19 & 0.07 & 1.17 & 0.23 & 0.19 \\
0.15 & 1.03 & 0.20 & 0.08 & 1.23 & 0.24 & 0.21 \\
0.20 & 1.05 & 0.20 & 0.09 & 1.29 & 0.24 & 0.23 \\
\hline
\end{tabular}

$Y$ is aggregate real value added, $s_{h}$ is the expenditure share of high-skilled services, and $n_{h}$ is the employment share of high-skilled services. $\tau_{i, 09}$ refers to the calibrated values in 2009 and $\tau_{i}=0$ refers to no barriers. The first row corresponds to $\Omega^{h}$ in the benchmark.

\section{Conclusion}

We have documented that the employment share of high-skilled services is much lower in China than in countries with similar GDP per capita. We have built a model of structural change between goods, low-skilled services, and high-skilled services to account for this observation. We have found that large distortions limit the size of high-skilled services in China. If they were removed, both high-skilled services and GDP per capita would increase considerably and the effects of technological progress and education on GDP per capita would be considerably larger. Our results suggests that distortions in high-skilled services hold back the development of China.

The previous results raise the question what nature the barriers/distortions in high-skilled services take. One possible distortion in high-skilled services is that state-owned enterprises, which are usually thought to be less efficient, are more prevalent in the high-skilled service sector than in the other sectors. It is well known that, on average, state-owned enterprises are more distorted and less productive than privately owned ones; see, for example, the discussion in Song et al. (2011). We have shown that, indeed, the employment share of state-owned enterprised tends to be much larger in high-skilled services than in the other sectors. In particular, state-owned enterprises employ more than half of the workers in high-skilled services, but less than one in twenty five of the workers in the other sectors. 


\section{References}

Alder, Simon, Timo Boppart, and Andreas Müller, "A Theory of Structural Change that Can Fit the Data," Manuscript 2017.

Baumol, William J., Sue Anne Batey Blackman, and Edward N. Wolff, "Unbalanced Growth Revisited: Asymptotic Stagnacy and New Evidence," American Economic Review, $1985,75,806-817$.

Boppart, Timo, "Structural Change and the Kaldor Facts in a Growth Model with Relative Price Effects and Non-Gorman Preferences," Econometrica, 2014, 82, 2167-2196.

Buera, Francisco J. and Joseph P. Kaboski, "The Rise of the Service Economy," American Economic Review, 2012, 102, 2540-2569.

— — - and Richard Rogerson, "Skill Biased Structural Change," Working Paper 21165, NBER 2015.

Cao, Kang Hua and Javier A. Birchenall, "Agricultural Productivity, Structural Change, and Economic Growth in Post-reform China," Journal of Development Economics, 2013, 104, $165-180$.

Comin, Diego, Martí Mestieri, and Danial Lashkari, "Structural Transformations with Long-run Income and Price Effects," Manuscript, Northwestern University 2015.

Dekle, Robert and Guillaume Vandenbroucke, "A Quantitative Analysis of China's Structural Transformation," Journal of Economic Dynamics and Control, 2012, 36, 119-135.

Duarte, Margarida and Diego Restuccia, "The Role of the Structural Transformation in Aggregate Productivity," Quarterly Journal of Economics, 2010, 125, 129-173.

_ and _ - "Relative Prices and Sectoral Productivity," Manuscript, University of Toronto 2016.

Duernecker, Georg, Berthold Herrendorf, and Ákos Valentinyi, "Structural Change within the Service Sector and the Future of Baumol Disease," Manuscript 2017.

Herrendorf, Berthold, Richard Rogerson, and Ákos Valentinyi, “Two Perspectives on Preferences and Structural Transformation," American Economic Review, 2013, 103, 2752-2789.

- - — and — "Growth and Structural Transformation," in Philippe Aghion and Steven N. Durlauf, eds., Handbook of Economic Growth, Vol. 2, Elsevier, 2014, pp. 855941. 
Hsieh, Chang-Tai and Peter J. Klenow, "Misallocation and Manufacturing TFP in China and India," Quarterley Journal of Economics, 2009, 74, 1403-1448.

Jorgenson, Dale W. and Marcel P. Timmer, "Structural Change in Advanced Nations: A New Set of Stylised Facts," Scandinavian Journal of Economics, 2011, 113, 1-29.

Katz, Lawrence F. and Kevin M. Murphy, "Changes in Relative Wages, 1963-1987: Supply and Demand Factors," Quarterly Journal of Economics, 1992, 107, 35-78.

Khor, Niny, Lihua Pang, Chengfang Liu, Fang Chang, DiMo, Prashant Loyalka, and Scott Rozelle, "Chinas Looming Human Capital Crisis: Upper Secondary Educational Attainment Rates and the Middle Income Trap,” REAP Working Paper 280, Stanford University 2015.

Meng, Xin, “Labor Market Outcomes and Reforms in China," Journal of Econimc Perspectives, 2012, 26, 75-102.

Nabar, Malhar and Kai Yan, "Sector-Level Productivity, Structural Change, and Rebalancing in China," IMF Working Paper, Washington DC 2013.

Restuccia, Diego, Dennis Tao Yang, and Xiaodong Zhu, "Agriculture and Aggregate Productivity: A Quantitative Cross-Country Analysis," Journal of Monetary Economics, 2008, 55, 234-50.

Song, Michael Zheng, Kjetil Storesletten, and Fabrizio Zilibotti, "Growing like China," American Economic Review, 2011, 101, 202-241.

Zhu, Xiaodong, "Understanding Chinas Growth: Past, Present, and Future," Journal of Economic Perspectives, 2012, 26, 103-124. 


\section{A Appendix: Classification into High- and Low-skilled Ser- vices Industries Does Not Change over Time}

Table A1: Share of High-skilled Workers in Industry Employment (in \%, Census Data)

\begin{tabular}{lccccccc}
\hline Industry & 2010 & 2000 & 1990 & 1980 & 1970 & 1960 & 1950 \\
\hline Low-skilled & & & & & & & \\
Transport \& Telecommunication & 20 & 18 & 14 & 10 & 5 & 3 & 1 \\
Wholesale \& Retail & 17 & 14 & 13 & 10 & 6 & 5 & 2 \\
Personal Services & 21 & 18 & 15 & 10 & 4 & 2 & 1 \\
Utilities & 29 & 20 & 19 & 13 & 8 & 7 & 2 \\
\hline High-skilled & & & & & & & \\
Business and Repair & 37 & 35 & 28 & 22 & 14 & 11 & 3 \\
Public Administration & 36 & 31 & 26 & 21 & 14 & 11 & 4 \\
Finance, Insurance, Real Estate & 44 & 37 & 31 & 23 & 16 & 13 & 4 \\
Professional Services & 49 & 46 & 44 & 41 & 38 & 38 & 17 \\
\hline
\end{tabular}

Data for 1950-2000 are constructed from IPUMS Census. Data for 2010 are constructed from IPUMS American Community Survey. 


\section{B Appendix: Model Solution}

\section{B.1 Solving for the Demand System}

Let $c_{i t}^{n}$ be the consumption of good $i$ by household $n$. From Roy's identity:

$$
c_{i t}^{n}=-\frac{\partial v\left(e_{t}^{n}, \vec{P}_{t}\right) / \partial p_{i t}}{\partial v\left(e_{t}^{n}, \vec{P}_{t}\right) / \partial e_{t}^{n}}
$$

Applying this to (2) gives:

$$
c_{i t}^{n}=-\frac{\left(e_{t}^{n} B_{t}^{-1}-A_{t}\right)^{\varepsilon-1}\left(-e_{t}^{n} B_{t}^{-2} B_{i t}-A_{i t}\right)+D_{i t}}{\left(e_{t}^{n} B_{t}^{-1}-A_{t}\right)^{\varepsilon-1} B_{t}^{-1}}=A_{i t} B_{t}+e_{t}^{n} B_{i t} B_{t}^{-1}-\left(e_{t}^{n} B_{t}^{-1}-A_{t}\right)^{1-\varepsilon} D_{i t} B_{t},
$$

where $A_{i t}, B_{i t}$ and $D_{i t}$ are the derivatives with respect to $p_{i t}$, respectively. Hence, we get the expenditure shares:

$$
\frac{p_{i t} c_{i t}^{n}}{e_{t}^{n}}=\frac{B_{t}}{e_{t}^{n}} p_{i t} A_{i t}+B_{t}^{-1} p_{i t} B_{i t}-\frac{B_{t}}{e_{t}^{n}}\left(e_{t}^{n} B_{t}^{-1}-A_{t}\right)^{1-\varepsilon} p_{i t} D_{i t}
$$

Following Proposition 3 in Alder et al. (2017), we can aggregate the expenditure shares for all households and derive $s_{i t}\left(\vec{P}_{t}, E_{t}\right)$ :

$$
s_{i t}\left(\vec{P}_{t}, E_{t}\right)=\frac{p_{i t} \sum_{n} c_{i t}^{n}}{E_{t}}=\frac{B_{t}}{E_{t}} p_{i t} A_{i t}+B_{t}^{-1} p_{i t} B_{i t}-\frac{B_{t}}{E_{t}}\left(E_{t} B_{t}^{-1}-A_{t}\right)^{1-\varepsilon} p_{i t} D_{i t} \kappa
$$

where $\kappa \equiv \sum_{n} \frac{\partial v}{\partial e}\left(\vec{P}_{t}, E_{t}\right) / \frac{\partial v}{\partial e}\left(\vec{P}_{t}, e_{t}^{n}\right)$. Derive $A_{i t}, B_{i t}$ and $D_{i t}$ and plug into (A.1):

$$
\begin{aligned}
s_{g t}\left(\vec{P}_{t}, E_{t}\right) & =\phi_{g}+\left(\mu_{g}-\phi_{g}\right) \frac{A\left(\vec{P}_{t}\right)}{E_{t} / B\left(\vec{P}_{t}\right)}+\left(\frac{E_{t}}{B\left(\vec{P}_{t}\right)}-A\left(\vec{P}_{t}\right)\right)^{1-\epsilon} \frac{B\left(\vec{P}_{t}\right)}{E_{t}} \sum_{k \in\{h, l\}} \bar{D} v_{k}\left(p_{k t} / p_{g t}\right)^{\psi_{k}} \kappa, \\
s_{i t}\left(\vec{P}_{t}, E_{t}\right) & =\phi_{i}+\left(\mu_{i}-\phi_{i}\right) \frac{A\left(\vec{P}_{t}\right)}{E_{t} / B\left(\vec{P}_{t}\right)}-\left(\frac{E_{t}}{B\left(\vec{P}_{t}\right)}-A\left(\vec{P}_{t}\right)\right)^{1-\epsilon} \frac{B\left(\vec{P}_{t}\right)}{E_{t}} \bar{D} v_{i}\left(p_{i t} / p_{g t}\right)^{\psi_{i}} \kappa, \quad i \in\{h, l\}, \\
\kappa & =\frac{\Omega_{t}^{l}\left(\frac{e_{t}^{l}}{B_{t}}-A_{t}\right)^{1-\epsilon}+\Omega_{t}^{h}\left(\frac{e_{t}^{h}}{B_{t}}-A_{t}\right)^{1-\epsilon}}{\left(\frac{E_{t}}{B_{t}}-A_{t}\right)^{1-\epsilon}} .
\end{aligned}
$$

\section{B.2 Solving for the Production Side}

Set $p_{g t}$ to its data value. The representative firm $i^{\prime} s$ problem is given by:

$$
\max p_{i t} y_{i t}-\left(1+\tau_{i t}\right)\left(w_{t}^{h} h_{i t}+w_{t}^{l} \ell_{i t}\right)
$$


Taking first-order conditions:

$$
\begin{array}{r}
p_{i t} Z_{i t} \alpha_{i t}\left(\frac{L_{i t}}{h_{i t}}\right)^{\frac{1}{\rho}}=w_{t}^{h}\left(1+\tau_{i t}\right), \\
p_{i t} Z_{i t}\left(1-\alpha_{i t}\right)\left(\frac{L_{i t}}{\ell_{i t}}\right)^{\frac{1}{\rho}}=w_{t}^{l}\left(1+\tau_{i t}\right) .
\end{array}
$$

The ratio of equations (A.2) and (A.3) gives:

$$
\frac{h_{i t}}{\ell_{i t}}=\left(\frac{\alpha_{i t}}{1-\alpha_{i t}}\right)^{\rho}\left(\frac{w_{t}^{l}}{w_{t}^{h}}\right)^{\rho} .
$$

Define $a_{i t} \equiv \frac{\alpha_{i t}}{1-\alpha_{i t}}$ and $\hat{w}_{t} \equiv \frac{w_{t}^{h}}{w_{t}^{l}}$. The above ratio becomes:

$$
\frac{h_{i t}}{\ell_{i t}}=a_{i t}^{\rho} \hat{w}_{t}^{-\rho} .
$$

Using (A.5), production function can be written as:

$$
y_{i t}=Z_{i t}\left(1-\alpha_{i t}\right)^{\frac{\rho}{\rho-1}}\left(a_{i t}^{\rho} \hat{w}_{t}^{1-\rho}+1\right)^{\frac{\rho}{\rho-1}} \ell_{i t}
$$

Define:

$$
\varphi_{i t}\left(\hat{w}_{t}\right) \equiv\left(1-\alpha_{i t}\right)^{\frac{\rho}{\rho-1}}\left(a_{i t}^{\rho} \hat{w}_{t}^{1-\rho}+1\right)^{\frac{\rho}{\rho-1}}
$$

$y_{i t}$ can be further rewritten as:

$$
y_{i t}=Z_{i t} L_{i t}=Z_{i t} \varphi_{i t}\left(\hat{w}_{t}\right) \ell_{i t} .
$$

Plugging (A.7) into the first-order condition (A.3) gives relative sectoral prices:

$$
\begin{aligned}
p_{i t} & =\frac{\left(1+\tau_{i t}\right) w_{t}^{l}}{Z_{i t}\left(1-\alpha_{i t}\right)} \varphi_{i t}\left(\hat{w}_{t}\right)^{-\frac{1}{\rho}}, \\
\frac{p_{i t}}{p_{j t}} & =\left(\frac{1+\tau_{i t}}{1+\tau_{j t}}\right)\left(\frac{1-\alpha_{j t}}{1-\alpha_{i t}}\right)\left(\frac{Z_{j t}}{Z_{i t}}\right)\left(\frac{\varphi_{j t}\left(\hat{w}_{t}\right)}{\varphi_{i t}\left(\hat{w}_{t}\right)}\right)^{\frac{1}{\rho}} .
\end{aligned}
$$

From (A.7) and (A.9):

$$
\frac{p_{i t} y_{i t}}{p_{j t} y_{j t}}=\left(\frac{1+\tau_{i t}}{1+\tau_{j t}}\right)\left(\frac{1-\alpha_{j t}}{1-\alpha_{i t}}\right)\left(\frac{\varphi_{j t}\left(\hat{w}_{t}\right)}{\varphi_{i t}\left(\hat{w}_{t}\right)}\right)^{\frac{1-\rho}{\rho}}\left(\frac{\ell_{i t}}{\ell_{j t}}\right) .
$$


From household's problem we know $s_{i}\left(\vec{P}_{t}, E_{t}\right)$. Hence the above equation can be rewritten as:

$$
\frac{p_{i t} y_{i t}}{p_{j t} y_{j t}}=\frac{s_{i}\left(\vec{P}_{t}, E_{t}\right)}{s_{j}\left(\vec{P}_{t}, E_{t}\right)}=\left(\frac{1+\tau_{i t}}{1+\tau_{j t}}\right)\left(\frac{1-\alpha_{j t}}{1-\alpha_{i t}}\right)\left(\frac{\varphi_{j t}\left(\hat{w}_{t}\right)}{\varphi_{i t}\left(\hat{w}_{t}\right)}\right)^{\frac{1-\rho}{\rho}}\left(\frac{\ell_{i t}}{\ell_{j t}}\right) .
$$

Thus:

$$
\frac{\ell_{i t}}{\ell_{j t}}=\left(\frac{1+\tau_{j t}}{1+\tau_{i t}}\right)\left(\frac{1-\alpha_{i t}}{1-\alpha_{j t}}\right)\left(\frac{\varphi_{i t}\left(\hat{w}_{t}\right)}{\varphi_{j t}\left(\hat{w}_{t}\right)}\right)^{\frac{1-\rho}{\rho}} \frac{s_{i}\left(\vec{P}_{t}, E_{t}\right)}{s_{j}\left(\vec{P}_{t}, E_{t}\right)} .
$$

(A.11) implies market clearing for low-skilled labor with $\ell_{g t}$ :

$$
\begin{aligned}
\Omega_{t}^{l} & =\sum \ell_{i t}, \\
\Omega_{t}^{l} & =\ell_{g t} \sum \frac{\ell_{i t}}{\ell_{g t}}, \\
\frac{\ell_{g t}}{\Omega_{t}^{l}} & =\frac{1}{\sum\left(\frac{1+\tau_{g t}}{1+\tau_{i t}}\right)\left(\frac{1-\alpha_{i t}}{1-\alpha_{g t}}\right)\left(\frac{\varphi_{i t}\left(\hat{w}_{t}\right)}{\varphi_{g t}\left(\hat{w}_{t}\right)}\right)^{\frac{1-\rho}{\rho}} \frac{s_{i}\left(\vec{P}_{t}, E_{t}\right)}{s_{1}\left(\vec{P}_{t}, E_{t}\right)}} .
\end{aligned}
$$

(A.11) and (A.5) imply market clearing for high-skilled labor with $\ell_{g t}$

$$
\begin{aligned}
\Omega_{t}^{h} & =\sum h_{i t}, \\
\frac{\Omega_{t}^{h}}{\Omega_{t}^{l}} & =\frac{\ell_{g t}}{\Omega_{t}^{l}} \sum \frac{h_{i t}}{\ell_{i t}} \frac{\ell_{i t}}{\ell_{g t}}, \\
\frac{\ell_{g t}}{\Omega_{t}^{l}} & =\frac{\Omega_{t}^{h} / \Omega_{t}^{l}}{\sum a_{i t}^{\rho} \hat{w}_{t}^{-\rho}\left(\frac{1+\tau_{g t}}{1+\tau_{i t}}\right)\left(\frac{1-\alpha_{i t}}{1-\alpha_{g t}}\right)\left(\frac{\varphi_{i t}\left(\hat{w}_{t}\right)}{\varphi_{g t}\left(\hat{w}_{t}\right)}\right)^{\frac{1-\rho}{\rho}} \frac{s_{i}\left(\vec{P}_{t}, E_{t}\right.}{s_{1}\left(\vec{P}_{t}, E_{t}\right)}} .
\end{aligned}
$$

The equilibrium is characterized by two equations with two unknowns $\left(\hat{w}_{t}, E_{t}\right)$. The first equation is obtained by equating (A.12) and (A.13). The second equation is $E_{t}=\sum p_{i t} y_{i t}$.

\section{Appendix: Calibration}

\section{Appendix: CHIP Data}

CHIP data is available for 1988, 1995, 1999, 2002, 2007, 2008, 2013. CHIP surveys urban and rural households separately every year. Since 2002, CHIP also separately survey migrant households. We did not use data for 1999 and 2008 because the 1999 survey only surveyed urban households and the 2008 survey has many observations of rural households with missing education information. We restrict our sample to be individuals older than 15 and employed.

We construct the ratio between high and low-skilled workers by sector separately from the rural, urban and migrant surveys. The composition of rural, urban and migrant workers has 
Figure A1: Share of High-skilled: Comparison with NBS

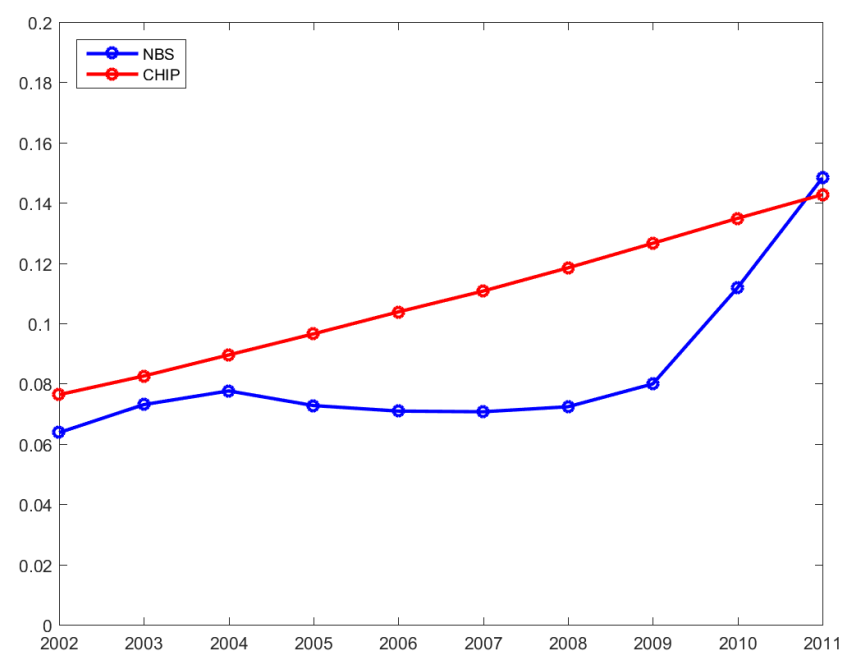

changed a lot in the Chinese workforce in the past 30 years. Because the survey does not provide survey weights, we weight the sectoral ratio between high and low-skilled workers by the fraction of urban workers, rural workers, and migrants provided by the National Bureau of Statistics (NBS). We then linearly interpolate the weighted sectoral ratios to get the ratio between high and low-skilled workers for the years for which CHIP data is not available. The employment by sector and by education is obtained by combining the ratios calculated from CHIP and the total employment by sector in the 10-sector database. As shown in the Appendix $\mathrm{D}$, the resulting share of high-skilled in the workforce is broadly consistent with that reported by the National Bureau of Statistics. 